\title{
Wohlrapp's Concept of Justification
}

\section{Derek AlLen}

Department of Philosophy

University of Toronto

170 St. George St.

Toronto, ON

Canada M5R 2M8

derekallen@trinity.utoronto.ca

\begin{abstract}
The first two sections of this paper jointly comprise an edited version of the commentary I presented in the panel discussion of Harald R. Wohlrapp, The concept of argument: A philosophical foundation at the OSSA 11 conference, May 2016. My principal focus was on a claim Wohlrapp makes about the extent to which his concept of justification is "reconcilable" with the views of current philosophers about justifications. Following the conference, Wohlrapp sent me a response to my commentary. In section 3, I report and reply to three of the comments he made in his response.
\end{abstract}

Résumé: Les deux premières sections de cet article comprennent conjointement une version éditée du commentaire que j'ai présenté lors de la table ronde sur Le concept d'argument: un fondement philosophique de Harald R. Wohlrapp, lors de la conférence OSSA 11, mai 2016. J'ai commenté principalement sur une déclaration énoncée par Wohlrapp sur la mesure dans laquelle son concept de justification est «réconciliable» avec les opinions des philosophes actuels sur les justifications. Après la conférence, Wohlrapp m'a envoyé une réponse à mon commentaire. Dans la section 3, je fais état de sa réponse et réponds à trois des commentaires qu'il a faits dans sa réponse.

Keywords: epistemic, epistemic justification, interpersonal justification, justification, orientation, truth

\section{Introduction}

Wohlrapp's concept of justification is linked to the concept he calls "orientation". He uses this term to designate "the pragmatic function of theses and theories" (p. $5^{1}$ ), that being to guide action and reflection. ${ }^{2}$ Theses are linguistic entities (sentences,

\footnotetext{
${ }^{1}$ Unless otherwise indicated, page references in sections 1 and 2 of this paper are to Wohlrapp (2014).

${ }^{2}$ Here I borrow words from David Hitchcock. In his contribution to this collection of commentaries on Wohlrapp's book, he says: "I use the phrase 'guide for action and reflection' as a replacement for Wohlrapp's word 'orien-
}

(C) Derek Allen, Informal Logic, Vol. 37, No. 3 (2017), pp. 170-182. 
propositions, speech acts, etc.) but primarily they are "new orientations" (p. lix). The ultimate goal of argumentation is to assess the validity of theses - that is, to determine whether they are reliable orientations (ibid.). A valid thesis is one that has been sufficiently backed by argumentation (p. xxxii). Only in a praxis does "the extent of the validity of a thesis" become apparent ( $p$. $1 \mathrm{x}$ ). "A thesis is valid if it can be justified in such a way that no objections remain" (p. 1xi).

Theories, as Wohlrapp understands them, are "verbal formations that open up any domains of reality at least to the extent that people are now able to act within them" (p. vi). They have the pragmatic function of providing practical orientation, and the validity claim that accompanies a theory is that the theory provides such orientation (p. 37). If this claim "has been satisfied in a particularly closed way" both theoretically and practically ("although it is only closed for the time being") then it is knowledge (ibid.).

\section{Justification}

“Someone who possesses a knowledge K 'knows' any set of propositions $\mathrm{p}_{1}-\mathrm{p}_{\mathrm{n}}$ if he believes them to provide reliable orientation based on a justification that utilizes $\mathrm{K}$ and if this belief is usually not disappointed" (p. 44). This is a pragmatic concept of knowledge; it requires a concept of justification (pp. 142-48; pp. 150-53), but it "does not require a concept of 'truth'. Instead, it provides the concept of a regularly reliable orientation which is derived from knowledge" (p. 44). But Wohlrapp adds: "Everything that could be formally derived from knowledge may then be termed 'true' or 'a truth"' (ibid.).

Suppose that on the basis of a justification that utilizes knowledge $\mathrm{K}, \mathrm{S}$ believes that proposition $p$ provides reliable orientation, and suppose that this belief is usually not disappointed. Then, if S's belief could be said to be formally derived from knowledge inasmuch as it is based on a justification that utilizes knowledge, it could be said to be true, and so in this way there would be a link between justification and truth.

A justification, as Wohlrapp understands it, has two components: a base and a transition from the base to a thesis.

tation' .... In a previous version of this article, I used 'basis for acting' as a replacement for 'orientation'. Wohlrapp objected that this paraphrase treated an orientation as too exclusively a guide to action" (Hitchcock 2017, p. 232, footnote 1).

(C) Derek Allen, Informal Logic, Vol. 37, No. 3 (2017), pp. 170-182. 
The base is epistemic theory, "no matter how rudimentarily crafted" (p. 144). Epistemic theory encompasses "knowledge, practical experience, and solid particular beliefs" (p. 2), and already functions as orientation in the actions and lives of the participants (p. 144). The participants comprise, at a minimum, a person who provides the justification and a person to whom the justification is addressed.

The transition in a justification is an "inferential step" ( $p$. 145) supported by theory. The supporting theory is a material conditional sentence which serves as a warrant for the inference and which "refers to action opportunities", thereby making it possible "for there to be steps in an argument that are 'new'that is, whose theoretical form has not yet been epistemically established, but is, for now, thetic" (ibid.).

The transition component of a substantial justification must include "elements of construction" (p. 148). These elements are either formal, as in logic and mathematics, or, "more typically, semiformal" (ibid.). Semiformal elements of construction are argumentation schemes which "can be analyzed as 'if... then' sentences that are relevant to questions of validity under certain specifiable conditions" (ibid.); for example, generalizations, slippery slope arguments, arguments from analogy, and arguments to the best explanation (ibid.).

A justification has "a subjective side" (p. 151). The addressee may understand the step(s) in the justification and may gain the insights "that are articulated by the thesis" (ibid.), but Wohlrapp says that whether she then follows her insights by acting "is not specified by the concept of justification as [he has] proposed it" (ibid.).

He also says that the concept of justification he proposes "is reconcilable with almost everything philosophers currently say about justifications" (p. 142). This is a striking claim, and in light of it I am going to consider whether Wohlrapp's concept of justification is reconcilable with an account of interpersonal justification given by the philosopher Alvin Goldman.

Goldman's account builds on an epistemological account of good argument very similar to one given by Richard Feldman. Goldman's epistemological account is the following:

An argument is a good argument [epistemologically] relative to a person $\mathrm{S}$ if and only if:

(i) $\mathrm{S}$ is justified in believing the conjunction of all the premises of the argument,

(ii) the argument is either valid or inductively strong, and

(iii) $\mathrm{S}$ is justified in believing that the premises are "properly connected" to the conclusion (1995, p. 57).

(C) Derek Allen, Informal Logic, Vol. 37, No. 3 (2017), pp. 170-182. 
Goldman distinguishes two senses of interpersonal justification (IP-justification). He says that "there is a justificationcreation sense of IP-justification, which only requires that the speaker create [personal] justification in the hearer, and a justification-transmission sense of IP-justification, which requires that the speaker herself have [personal] justification for [a proposition Y], which she transmits to the hearer" (ibid., p. 59).

Goldman defines transmissional IP-justification as follows:

Speaker S IP-justifies proposition Y to hearer S* (in the justification-transmission sense) if and only if:

(i) $\mathrm{S}$ presents an argument $\mathrm{A}$ to $\mathrm{S}^{*}$, of which $\mathrm{Y}$ is the conclusion,

(ii) argument A is an (epistemologically) good argument relative to both $S_{\text {and }} \mathrm{S}^{*}$, and

(iii) $\mathrm{S}^{*}$ comes to believe $\mathrm{Y}$ by inference from the premises of $\mathrm{A}$ and appreciation of the proper connection between premises and conclusion (ibid.).

Goldman also defines creational IP-justification; his definition is the same as his definition of transmissional IPjustification, except that there is no reference to speaker $\mathrm{S}$ in clause (ii). A speaker who creates IP-justification in another person might not herself have personal justification for the proposition concerned. I think Wohlrapp would regard his account of justification as an account of transmissional IP-justification, but if he would consider it an account of creational IP-justification this wouldn't make a significant difference for a response to the reconcilability question, to which I now turn.

First, a definitional point. In one sense, to reconcile two things is to make or show them to be compatible (NODE 1999). Thus, theory of justification A is reconcilable with theory of justification $\mathrm{B}$ if $\mathrm{A}$ and $\mathrm{B}$ can be shown to be compatible, or if $\mathrm{A}$ and B can be made compatible. Wohlrapp's reconcilability claim would permit him to say (supposing he believed this to be true) that his account of justification is in the indicated sense reconcilable with "almost everything" Goldman says about IPjustification. Is it? I will next consider some matters that bear on this question.

(a) Wohlrapp says that his concept of justification is "pragmatic and dialogical... [I]t construes the potential certainties that can be generated by an argumentative justification as resulting from a practical basis. Moreover, it includes the notion of examining a thesis by way of a critical dialogue" (p. 142). Wohlrapp makes these remarks immediately after making his 
reconcilability claim; thus, he evidently doesn't regard them as undermining that claim. And they don't necessarily undermine it, for a pragmatic and dialogical account of justification might be compatible with an account that is neither pragmatic nor dialogical.

Goldman's account of IP-justification is such an account. It's not pragmatic; rather, it's epistemic. And it's not dialogical. Nevertheless, Goldman could grant that a basic premise in an IP-justification (i.e., a premise not supported in the argument itself) might, depending on its content, count as a theory in Wohlrapp's sense, have a practical basis, and be considered to be, in Wohlrapp's terms, an orientation for a new domain ( $p$. 147); he could also grant that the same might be true of the conclusion of an IP-justification. Goldman's account doesn't include the idea of examining a thesis in a critical dialogue, or, then, the idea, emphasized by Wohlrapp, of defending justifications against objections in critical dialogue and revising them if necessary (p. 1xi); but Goldman's account accommodates inductive arguments, and, as James Freeman has noted, one way to test an inductive argument "is to bring objections against it" (1993, p. 230).

(b) Goldman's account of IP-justification includes his account of each of the two types of IP-justification he distinguishes - the creational and the transmissional. According to clause (i) in his account of transmissional IP-justification, proposition $\mathrm{Y}$ is the conclusion of an argument. For Wohlrapp, a justification justifies a thesis. In his view, "a thesis and a conclusion differ in their pragmatic function. The thesis claims to be suitable as a new orientation. In the conclusion, this claim is satisfied if this is made possible by the proposed argumentation" (p. 134). It doesn't follow from the preceding sentence that a thesis supported by argument counts as a conclusion only if the claim made by the thesis is satisfied by the argument. This being so, Wohlrapp is free to call a thesis supported by argument the conclusion of the argument that supports it.

(c) Goldman's account of transmissional IP-justification requires that the speaker and hearer be justified in believing the conjunction of the premises of the justification - that is, justified in believing their conjunction to be true. Wohlrapp, on the other hand, might say that if a justification is to succeed, the addressee must be justified in believing that the premises provide reliable orientations. Here there would be a difference between Wohlrapp's account and Goldman's. There would not necessarily be an incompatibility, however, because being justified in believing the conjunction of the premises of a justification to be true does 
not preclude also being justified in believing that these premises provide reliable orientations; indeed, in a particular case one might be justified in holding the latter belief because (or partly because) one was justified in holding the former. A related point is this. A successful Wohlrappian justification will show that the validity claim raised by the thesis, namely that the thesis provides a reliable orientation, is true unless subsequent critical dialogue shows otherwise.

(d) For Goldman, an argument in which speaker S successfully justifies proposition $\mathrm{Y}$ to hearer $\mathrm{S}^{*}$ is either valid (meaning deductively valid) or inductively strong. In Wohlrapp's view, “justifications ... may contain deductive steps, [but] these are non-compelling overall" (p. 146). Deductive reasoning, he holds, merely transforms existing knowledge; it doesn't produce new knowledge (p. 147). As for "induction", Wohlrapp thinks that this term "is no longer a suitable designation for justifications that are constructive and substantial" ( $p$. 146, n. 25). He prefers the term 'epagogic'. Epagogic justifications "lead (our understanding) from the assumed basis to the thesis in question" (p. 146). But this view allows Wohlrapp to hold that successful epagogic justifications provide strong but nonconclusive support for their conclusions if they aren't defeated by objections, and so it allows him to hold that successful epagogic justifications are inductively strong.

(e) Goldman's account of transmissional IP-justification requires that $\mathrm{S}$ and $\mathrm{S}^{*}$ be justified in believing that the premises of the argument concerned are "properly connected" to conclusion $\mathrm{Y}$ and that $\mathrm{S}^{*}$ come to believe $\mathrm{Y}$ by inference from the premises and appreciation of their "proper connection" to $\mathrm{Y}$. Wohlrapp's account permits the requirement that for a justification to be successful the addressee be justified in believing that the transition from base to thesis is warranted by the theory that supports it and that, consequently, base and thesis are "properly connected"; Wohlrapp's account also permits the view that the addressee comes to believe the thesis by inference from the base and "appreciation" of the "proper connection" between base and thesis as judged by what Wohlrapp would take to be appropriate standards of assessment. Here too there is compatibility between the two accounts.

(f) Goldman's account allows that the conclusion of an IPjustification may be false, for if the argument is inductive the conclusion may be false even if the premises are true. Does Wohlrapp's account allow that the thesis which is the conclusion of a justification may not be valid - that is, may not represent a valid orientation? Perhaps not, for Wohlrapp says that a justifi- 
cation "demonstrates the validity of a thesis" (p. 152; italics added). But here Wohlrapp is using the term 'justification' as a "success" term, such that a justification necessarily succeeds in justifying its thetic conclusion. In another sense, however, to justify a thesis is simply to provide reasons in support of it. A thesis which is in this sense justified might not be valid-it might fail to represent a valid orientation. This is certainly possible on Wohlrapp's view that justifications are epagogic, hence nonconclusive. Indeed, it seems that Wohlrapp must accept that the thetic conclusion of a justification need not be a valid orientation, because in his view such a thesis might be refuted by subsequent objections made in critical dialogue.

The preceding considerations lead me to think that, so far at any rate, we have no reason to believe that Wohlrapp's concept of justification is not, in the relevant sense, reconcilable with "almost everything" Goldman says in his account of IPjustification.

\section{Comments by Wohlrapp}

Following the OSSA 11 conference, Wohlrapp sent me comments in response to my commentary on his book. In this section, I report and reply to three of the comments he made in his response; I label these comments " $W(1)$ ", " $W(2)$ ", and " $W(3)$ ".

$W(1)$ : In my view validity (as the attempted result of a justification) and acceptance are separated. Validity depends on the quality of the arguments whereas acceptance is independent of that quality. This makes my concept an "epistemic" one - or, better, because of this salient theoretical feature my view is compatible with the epistemic approach.

The proper epistemic approach, however, struggles with unclarities concerning as well the believability of premises as with the quality of the conclusion of a good but not compelling argument. I will shortly sketch these and then allude [to] how a pragmatic foundation can help clarifying things.

There are two questions which might be considered. First: How can we be justified to believe the "premises" of an argument if they are not clearly true? I don't know if the epistemic approaches provide a unified answer. Goldman seems to claim, that one can be "personally justified" to believe P, insofar as one has an argument for $\mathrm{P}$, how good or bad it might ever be.

Reply: I don't think Goldman makes this claim or is otherwise committed to it. He thinks of "a person's justification as a matter of the evidence possessed by the person" and of evi- 
dence-possession as consisting of "the person's having certain beliefs and/or perceptual experiences" (1995, p. 58). A crucial point in this context concerns the concept of a justified belief. In one sense, a justified belief is a belief that has undergone a process of being justified (hence has been justified by means of an argument); in another sense, a justified belief is a belief that is "quite in order from the point of view of the standards for what I may reasonably believe"-for example, in virtue of "arising in the normal way [it has] from my perceptions" (Audi 1988, p. 1). Given this distinction, Goldman needn't claim that "one can be 'personally justified' to believe $\mathrm{P}$, insofar as one has an argument for P, how good or bad it might ever be". A person can be justified in holding a certain belief even if $s /$ he doesn't have an argument for that belief and has not been given an argument for it by another person. For example, I am justified, on the basis of my present perceptual experiences, in believing that I am now typing these words.

$W(2)$ : What is the quality of a conclusion that is "justifiably believed" (as e.g. in Goldman's epistemic account of IPjustification)? If it is knowledge, then the essential premises must already have been known and the inference must be formally valid.

Reply: Audi (and I believe Goldman) would agree with the first conjunct in the consequent of Wohlrapp's second sentence but not with the second conjunct. Audi:

Inference transmits justification and knowledge; it is not a basic source of them. It can generate them only derivatively, by transmission from knowledge and justification already possessed.... Deductive transmission apparently requires validity; and inductive transmission apparently requires an inductive counterpart of validity, something like a strong relation of support between premises and conclusion (1998, p. 75).

Since Audi allows for inductive transmission of justification and knowledge, he would not endorse Wohlrapp's requirement of formal validity; nor, I believe, would Goldman.

$W(3)$ : But are we clear about what is the "knowability" of a proposition that is not known? In my view the "thetic validity" is a good characterization of that quality. It consists of (a) providing insight and trust into the suitability of the conclusion to function as a new orientation together with (b) the positive result of the examination that there are no open objections any more against that conclusion. 
The upshot of these considerations is, that the epistemic approach urges for a pragmatist foundation.

Reply: Consider the following example:

(1) Patient $\mathrm{P}$ has symptoms $\mathrm{S}_{1}$ and $\mathrm{S}_{2}$.

Therefore probably,

(2) Patient P has illness X.

This argument depends on a background statistical generalization. Assume that the generalization is: $(G) 75 \%$ of people with symptoms $S_{1}$ and $S_{2}$ have illness $X$. Assume further that this generalization is based on a large and representative sample of people with symptoms $\mathrm{S}_{1}$ and $\mathrm{S}_{2}$.

Patient P's physician arranges for $\mathrm{P}$ to have tests done. The results are positive: $\mathrm{P}$ has illness $\mathrm{X}$ (I here assume that there is no countervailing evidence). Hence the physician arranges for $\mathrm{P}$ to undergo treatment $\mathrm{T}$.

Comments:

(a) If the test results had been negative, then, other things being equal, the conclusion of the above argument would have been false, and so would not have been knowledge.

(b) A pragmatist treatment of the example: Given generalization $\mathrm{G}$ (which I believe would count as a theory on Wohlrapp's account of theories) and the above assumption concerning the basis for it, and given the fact that the test results were positive and the assumption that there is no countervailing evidence (hence no open objections to the conclusion), the conclusion that $\mathrm{P}$ has illness $\mathrm{X}$ is sufficiently backed by argumentation, and so is a valid thesis. Accordingly, the conclusion is suitable "to function as a new orientation"; thus, it is suitable to guide actions (compare Wohlrapp's comment that "a thesis ... guides actions" (2014, p. 69)). In this case, it leads the physician to arrange for $\mathrm{P}$ to undergo treatment $\mathrm{T}$.

(c) Next, the following treatment of an expanded version of the example. P's physician is justified in believing the stated premise of the argument on the basis of her physical examination of $\mathrm{P}$ and on the basis of P's testimony, which the physician has reason to regard as trustworthy given her long acquaintance with $\mathrm{P}$. The physician is also justified in believing generalization $\mathrm{G}$, on the basis of her familiarity with the relevant medical literature. She recognizes that the conditional probability of the conclusion given the truth of the stated premise and generalization $\mathrm{G}$ is .75. Accordingly, she orders tests. She is justified in believing that the test results are positive, given her own direct inspection of the X-rays that were done and given her confidence, 
based on experience, in the competence of the clinical lab that conducted the tests. She is also justified in believing that there is no countervailing evidence, given that the tests were comprehensive and given that, as reported in the relevant medical literature (with which she is very familiar), such tests have been found to be highly reliable. Accordingly, she is justified in believing that $\mathrm{P}$ has illness $\mathrm{X}$; more specifically, she is epistemically justified in believing this. In addition, she knows that treatment $\mathrm{T}$ has been found to be highly effective in treating illness $X$. Accordingly, she arranges for $P$ to undergo treatment $T$.

(d) The story told in comment (c) is a story of epistemic justification that guides action at two stages: at the stage of ordering tests and at the stage of arranging for $\mathrm{P}$ to undergo treatment T. I see no reason to say that "the epistemic approach" illustrated in the comment (c) story "urges for a pragmatist foundation". It stands perfectly well on its own feet. The comment (b) pragmatist story and the comment (c) epistemic story are complementary and hence "reconcilable" with one another. In the following comment, I will say more about epistemic justification.

(e) According to Laurence Bonjour, epistemic justification is "the species of justification appropriate to knowledge" (1985, p. 7). Bonjour asks: "Why should we, as cognitive beings, care whether our beliefs are epistemically justified? Why is such justification something to be sought and valued?" (ibid.). Bonjour's "first approximation" answer: "What makes us cognitive beings at all is our capacity for belief, and the goal of our distinctively cognitive endeavours is truth: we want our beliefs to correctly and accurately depict the world.... The basic role of justification is that of a means to truth" (ibid.).

Wohlrapp proposes a pragmatic concept of knowledge (2014, p. 44); as noted in section 2 , it requires a concept of justification but "does not require a concept of 'truth'. Instead, it provides the concept of a regularly reliable orientation which is derived from knowledge" (ibid.). However, Wohlrapp grants (as also noted in section 2) that "[e]verything that could be formally derived from knowledge may then be termed 'true' or 'a truth"' (ibid.). Thus, Wohlrapp's pragmatic concept of knowledge requires the concept of 'a truth' but not a concept of 'truth'hence not a particular theory of truth. His pragmatic concept of knowledge also requires a concept of justification. One may wonder, then, whether it permits a concept of epistemic justification understood as Bonjour understands it. If it doesn't, then this marks a decisive difference between Wohlrapp's concept of justification and what one philosopher (Bonjour) says about "the 
species of justification appropriate to knowledge", and this would clearly be relevant to Wohlrapp's reconcilability claimall the more so if, as I believe, Bonjour's concept of epistemic justification would be endorsed by many analytic epistemologists.

However, I think Wohlrapp's pragmatic concept of knowledge can accommodate Bonjour's concept of epistemic justification. Consider Wohlrapp's apple example (2014, pp. 136-37):

(a) This apple is not ripe yet.

Wohlrapp imagines a "discursive situation" in which a mother talks to her little boy, "who is not aware of this fact" (2014, p. 137; italics added) - i.e., the fact that this apple is not ripe yet.

The mother is able to present evidence for the apple's unripeness (color, odor) with which the boy is not familiar. She and her son are situated at different points along an "epistemic slope." For her, the sentence is not thetic [i.e., for her, it isn't a new orientation]. For him, it is. If he expresses doubts, she could introduce him to external indicators of ripeness in apples. If she is clever, then she does this in a way that allows his understanding to grow gradually, all the while responding to possible questions and objections. (This is "pedagogical argumentation.") (Ibid.; italics added).

This example is open to the following interpretation. The mother believes that the apple isn't ripe yet. Her belief is based on evidence-“external indicators" of the apple's unripeness. Hence, her belief is justified in the sense that (to adapt words of Audi's quoted above) it is "quite in order from the point of view of the standards for what [she] may reasonably believe". (This is so, I would add, partly because, as far as we can tell, at the time she acquires the belief she has no equally strong or stronger evidence to the contrary.) The justification that the evidence provides for her belief is epistemic because it is a means to truth (in the matter of whether the apple is unripe) and so is "appropriate to knowledge" (Bonjour 1985, p. 7). The mother transmits to her son her justification for her belief that the apple isn't ripe, and so he acquires an epistemically justified belief that it isn't ripe (assuming that she successfully answers any questions or objections he may have). As a result, sentence (a) is now thetic for him - a new orientation, hence a sentence which has pragmatic (action-guiding) significance for him (though precisely what orientation value it has for him is left open: this may depend on 
his desires/preferences, if any, concerning unripe apples). In this story, epistemic justification, as construed by Bonjour, plays a central role in a case of "pedagogical argumentation" that has a pragmatic outcome - the creation of a new orientation for the addressee.

There may, however, be discursive situations of other sorts in which the justification provided for a thesis isn't epistemic justification in Bonjour's sense. But even if there are, it seems to me that Wohlrapp can accommodate Bonjour's concept of epistemic justification in his pragmatic concept of knowledge and deploy it where it fits, as in the apple example.

Suppose I am wrong about this-suppose that Bonjour's concept of epistemic justification is utterly alien to Wohlrapp's pragmatic concept of knowledge. Wohlrapp's claim that his proposed concept of justification "is reconcilable with almost everything philosophers currently say about justifications" (2014, p. 142; italics added) might nevertheless be true. But even if it is true, it could also be true that of those things philosophers currently say about justifications with which Wohlrapp's concept is not reconcilable, one is an essential difference between his concept of justification and theirs, in which case his concept isn't reconcilable with theirs. A fortiori, if there is an essential difference between Wohlrapp's concept of justification and Bonjour's concept of epistemic justification, then Wohlrapp's concept isn't reconcilable with Bonjour's. This is especially noteworthy if it is the case (as I said above I believe it is) that Bonjour's concept of epistemic justification would be endorsed by many analytic epistemologists.

\section{Conclusion}

In section 2 of this paper, I considered Wohlrapp's reconcilability claim in relation to Goldman's account of interpersonal justification and concluded that the considerations I presented there gave us no reason to believe that Wohlrapp's concept of justification isn't reconcilable, in the relevant sense, with "almost everything" Goldman says in that account. Nor, I think, do the comments of Wohlrapp's that I considered in section 3 give us reason to believe so.

In section 3, I claimed that Wohlrapp's pragmatic concept of knowledge can accommodate Bonjour's concept of epistemic justification. In addition, I referred to views about justification held by Audi. I will add here that Audi's concept of belief justification (by which he means justifiably believing) is an epistem- 
ic concept: "[w]ithout belief justification (or something very much like it) ... there would be no knowledge" (1988, p. 2). As far as I can see, Wohlrapp need not disagree.

Acknowledgements: I am grateful to the two Informal Logic reviewers of an earlier version of this paper for their comments, and to Harald Wohlrapp for his comments on my OSSA 11 panel commentary on his book.

\section{References}

Audi, Robert. 1988. Belief, justification, and knowledge. Belmont, California: Wadsworth, Inc.

Bonjour, Laurence. 1985. The structure of empirical knowledge. Cambridge, Mass. and London, England: Harvard University Press.

Freeman, James. 1993. Thinking logically: Basic concepts for reasoning. Englewood Cliffs, NJ: Prentice Hall.

Goldman, Alvin I. 1995. Argumentation and interpersonal justification. In Proceedings of the third conference of the International Society for the Study of Argumentation, eds. Frans H. van Eemeren, Rob Grootendorst, Charles A. Willard, Vol. 1, 53-61. Amsterdam: SicSat.

Hitchcock, David. 2017. Transsubjectivity. Informal Logic 37(3): 230-239.

NODE. 1999. The new Oxford dictionary of English. Oxford: Oxford University Press.

Wohlrapp, Harald R. 2014. The concept of argument: A philosophical foundation. Dordrecht: Springer Science \& Business Media. 